DE

M E D I C I N A

T R O P I C A L

$\mathrm{DE}$

SÃO PAULO

JOURNAL OF THE SÃO PAULO INSTITUTE OF TROPICAL MEDICINE

${ }^{1}$ Fundação Oswaldo Cruz, Recife, Instituto Aggeu Magalhães, Departamento de Saúde Pública, Recife, Pernambuco, Brazil

2Universidade Federal de Pernambuco, Programa de Pós-Graduação em Saúde Coletiva, Recife, Pernambuco, Brazil

${ }^{3}$ Fundação Joaquim Nabuco, Diretoria de Pesquisas Sociais, Recife, Pernambuco, Brazil

${ }^{4}$ Universidade de Pernambuco, Programa de Pós-Graduação Stricto Sensu em Ciências da Saúde, Recife, Pernambuco, Brazil

${ }^{5}$ Universidade Federal de Pernambuco, Departamento de Engenharia Cartográfica, Recife, Pernambuco, Brazil

${ }^{6}$ Fundação Oswaldo Cruz, Instituto Aggeu Magalhães, Departamento de Parasitologia, Recife, Pernambuco, Brazil

Correspondence to: Celivane Cavalcanti Barbosa

Fundação Oswaldo Cruz, Instituto Aggeu Magalhães, Departamento de Saúde Pública, Av. Professor Moraes Rego, s/n, Cidade Universitária, CEP 50740-465, Recife, PE, Brazil

Tel: +55 81 2101-2662,

+558199972-0418

E-mail: celivane.cb @ gmail.com

Received: 14 January 2020

Accepted: 28 September 2020

\section{Spatial analysis of epidemiological and quality indicators of health services for leprosy in hyperendemic areas in Northeastern Brazil}

\author{
Celivane Cavalcanti Barbosa ${ }^{(1}$, Cristine Vieira do Bonfim ${ }^{\oplus 2,3}$, Cintia \\ Michele Gondim de Brito ${ }^{(1)}$, Wayner Vieira de Souza ${ }^{(1)}$, Marcella Fernandes \\ de Oliveira Melo ${ }^{5}$, Zulma Maria de Medeiros ${ }^{(1,6}$
}

\section{ABSTRACT}

Leprosy is a public health problem due to the physical disabilities and deformities it causes. This study aimed to describe new leprosy cases using an operational classification and analyzing spatial patterns by means of epidemiological and quality indicators of health services in Pernambuco State, Brazil, between 2005 and 2014. This was an ecological study performed in 184 municipalities grouped into 12 health regions units for analysis. To analyze spatial patterns, the Bayesian local empirical method and Moran's spatial autocorrelation indicator were applied and box and Moran maps were used. Individuals aged $\geq 15$ years old, grade zero physical disability and complete remission as the treatment outcome were predominant in both paucibacillary and multibacillary cases, the only difference was the predominance of females $(n=9,286 ; 63.00 \%)$ and males $(n=8,564 ; 60.70 \%)$, respectively. These variables were correlated $(\mathrm{p}<0.05)$ with the operational classification. The overall detection rate showed three high-priority areas; the indicator rate of grade 2 physical disability revealed clusters in regions IV, V, and VI; and the indicator rate of cases with some degree of disability showed precarious municipalities in seven health regions. Pernambuco maintains an active chain of transmission and ongoing endemicity of leprosy. Therefore, spatial analysis methods allow the identification of priority areas for intervention, thereby supporting the disease elimination strategy.

KEYWORDS: Leprosy. Epidemiology. Health information systems. Spatial analysis.

\section{INTRODUCTION}

Leprosy is caused by Mycobacterium leprae, an obligate intracellular bacterium that primarily affects the peripheral nervous system. It is transmitted from personto-person through repeated contact with untreated multibacillary patients ${ }^{1}$.The diagnosis is essentially clinical and epidemiological, i.e., diagnosis is based on the individual's clinical history and living conditions ${ }^{2}$. The disease is associated with a wide spectrum of clinical manifestations divided into four forms, according to the Madrid classification: indeterminate, tuberculoid, dimorphi, and lepromatous (or Virchowian) ${ }^{3}$. The clinical forms are grouped for operational treatment purposes into paucibacillary (up to five skin lesions) and multibacillary (more than five skin lesions $)^{4}$. Currently, the primary strategies of elimination are early detection and treatment of patients ${ }^{5}$.

In 2014, the World Health Organization (WHO) identified 145 endemic countries with 174,554 new cases of leprosy, Southeast regions in Asia having the highest 
prevalence, followed by the American continent ${ }^{5}$. Brazil, India and Indonesia account for $81 \%$ of new leprosy cases worldwide $^{6}$. In 2014, approximately 31,000 new cases were reported in Brazil, with an annual detection rate of 15.32 per 100,000 inhabitants, the second highest annual number of new leprosy cases worldwide ${ }^{7,8}$. The Northern, Midwest, and Northeastern regions of Brazil have high detection rates ${ }^{8}$.

To monitor the progress of leprosy elimination and assess the quality of health care services, the Ministry of Health in Brazil uses a set of nine epidemiological and six operational indicators ${ }^{5}$. These indicators reflect activities that promote early detection of cases and surveillance of transmission foci, contributing to the monitoring and assessing strategies for the elimination and control of leprosy9.

Epidemiological, environmental and social indicators also serve to analyze health phenomena in space ${ }^{10}$. The spatial distribution of a disease in a given location may be evaluated using indicators. Spatial analysis provides a better understanding of disease dynamics in space ${ }^{11}$.

Research on spatial analysis and leprosy has as the main objective to understand the relationship of the disease with respect to space ${ }^{10-12}$. They have shown the priority areas of intervention and pointed out the associated factors that directly influence the process of determining the occurrence of this disease in human populations ${ }^{11,12}$.

Therefore, priority areas for the occurrence of leprosy can be identified to improve prevention and control strategies of the disease ${ }^{12}$. New cases can be characterized and assigned to an operational class to improve understanding of the continuity of the leprosy transmission chain. In addition, priority areas should be identified for the intervention and development of more effective disease control strategies. Thus, this study aimed to describe new leprosy cases using the operational classification and analyze spatial patterns using epidemiological and quality indicators of health services in hyperendemic areas in Northeastern Brazil.

\section{METHODS}

\section{Ethics statement}

This research project was approved by the Ethics Committee of the Institute Aggeu Magalhaes/Foundation Oswaldo Cruz (CAEE No 57922816.3.0000.5190).

\section{Study area}

This study was conducted in Pernambuco State, located in the Northeastern region of Brazil. It is composed of 184 municipalities and a State district (the island of Fernando de Noronha), which are distributed into 12 health regions. The State district was excluded from this study because it is located $545 \mathrm{~km}$ from Recife, the State capital.

The Health Region I stands out in the socio-demographic and economic data, as it comprises the municipalities of the Metropolitan Region and the State capital, concentrating approximately $44 \%$ of the State's population, in addition to having the largest hospital network. The highest mean GDP values per capita (in billions) and current values of GDP (Gross Domestic Product in millions of the Brazilian currency - reais) are found in regions I, IV, VIII and XII where industrial and commercial hubs predominate, consequently the best sanitary facilities are in these areas. The lowest socio-demographic and economic values were found in regions V and IX. However, the worst values in relation to the National Health Service (SUS) and coverage of the Family Health Teams were found in the I, IV and VIII Health Regions (Table 1) ${ }^{13}$.

\section{Study population}

This was an ecological study of new leprosy cases among Pernambuco State residents, between 2005 and 2014. Data were obtained from the Notifiable Diseases Information System (Sistema de Informacao de Agravos de Notificacao - SINAN), which integrates information on diseases of the Brazilian epidemiological surveillance system (Vigilancia Epidemiologica do Brasil) ${ }^{14}$. Data were collected from individual notification forms and leprosy follow-up reports (Boletim de Acompanhamento de Hanseniase). The study excluded the cases with diagnostic errors, duplicate entries, missing dataand inconsistencies such as the elements used to identify duplicate entries were the full name of the assisted individual, date of birth, mother's name, as well as dates of notification, diagnosis and treatment initiation; cases identified as having identical patient details were deemed as duplicate entries; inconsistences were analyzed based on duplicate data detected in new cases regarding the operational classification, clinical form, date of diagnosis and treatment initiation. In addition, transfers, recurrence, other re-entry and ignored cases were also excluded from the input mode field, so that only new cases remained in the input mode field (an individual who had never received specific treatment for the disease).

Regarding data completeness, the fields left answered as "unknown" were deemed incomplete and study variables were analyzed according to the classification of completeness by Oliveira et al. ${ }^{15}$ (excellent $\geq 90 \%$; average $70-89 \%$; and poor $<70 \%$ ). Cases classified as poor were excluded from the study. Only the variable bacilloscopy was excluded because these had a data completeness of $59.89 \%$. 


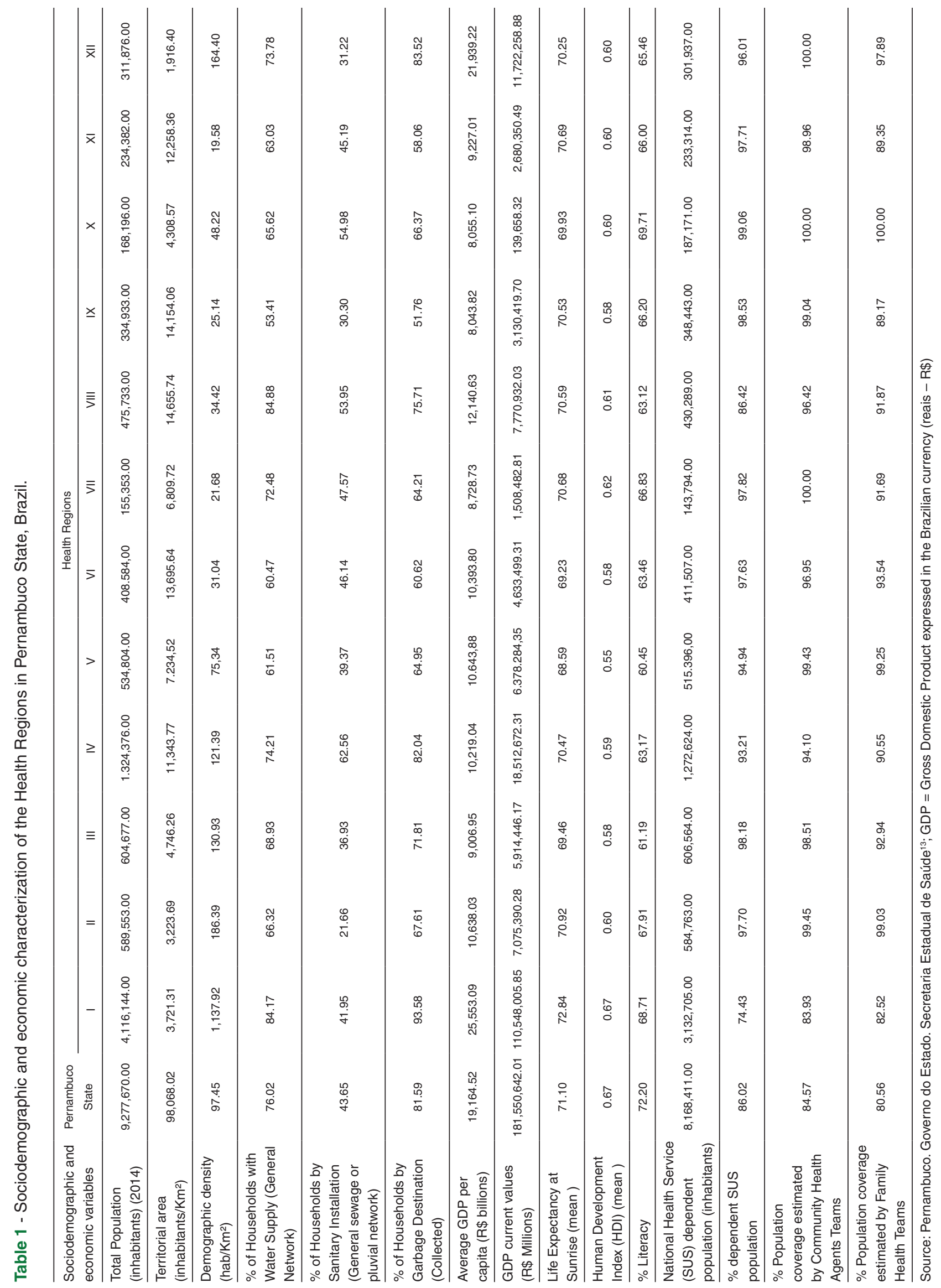




\section{Data management and analysis}

The analyzed variables were as follows: year of diagnosis, sex, age group, operational classification, assessment on the degree of physical disability at the time of diagnosis and treatment outcome. Two epidemiological indicators were used to determine disease trends and assess the timely detection of cases while two operational indicators were used to evaluate the quality of care in health services, and to ensure the surveillance of household contact to detect new cases. The Brazilian Ministry of Health adopts these indicators (Table 1) ) $^{5,16}$.

Two epidemiological indicators were selected for the spatial analysis (mean annual detection rate and leprosy rate with grade 2 physical disability), in addition to one operational indicator (new leprosy rate with some degree of physical disability) per municipality. The mean annual detection rate was calculated using the mean of new cases in the study period as the numerator and the population at the mid-point of this as the denominator. The population data were obtained from the Brazilian Institute of Geography and Statistics (IBGE) ${ }^{17}$ and was estimated for the general population used.

The association between the variable operational classification (paucibacillary and multibacillary) and sex, age group, assessment of the degree of physical disability at the time of diagnosis and treatment outcome was determined using the chi-square $\left(\chi^{2}\right)$ test, with a significance level of 0.05 . In addition, absolute and relative frequencies were calculated for each variable. All analyses were performed using the free R software, version 3.4.0 (Ross Ihaka and Robert Gentleman, Auckland, New Zeland). Absolute and relative frequency rates were calculated.

In the exploratory analysis of spatial data, the analysis unit was the municipality, the Bayesian local empirical method was used to minimize the instability caused by random fluctuation of rates, since the estimator calculates a weighted rate considering area variances ${ }^{18}$. The neighborhood matrix defined by adjacency of TerraView software, version 4.2 (Instituto Nacional de Pesquisas Espaciais - INPE, Sao Paulo, Brazil), was used for this Subsequently, the spatial autocorrelation was applied using the global Moran's index, the analysis remaining on the indicators that gave autocorrelations. Moran's index varies between -1 and +1 , where zero indicates no spatial autocorrelation and values near +1 and -1 indicate positive or negative spatial autocorrelation, respectively ${ }^{19,20}$.

Moran's scatterplot was used to visualize the spatial dependence. The plot shows normalized values that allow analysis of the spatial behavior of data ${ }^{20}$. Thus, the value of each municipality can be compared with those of neighboring municipalities, in the following manner: quadrants $1(\mathrm{Q} 1$, positive values and means) and $2(\mathrm{Q} 2$, negative values and means) indicate locations that have neighbors with similar values; quadrants $3(\mathrm{Q} 3$, positive values and negative means) and 4 (negative values and positive means) indicate locations that have neighbors with different values.

Next, Local Indicators of Spatial Association (LISA) were used to detect locally correlated regions, at significance levels of $95 \%, 99 \%$ and $99.9 \%$, and a LISA map19 was generated. However, this map is not shown here because it was only used to create the Moran map, which combines areas with positive spatial autocorrelation (identified in the box map) with spatial significance $>95 \%$ (indicated in the LISA map), i.e., it presents areas with statistical significance $(\mathrm{p}<0.05)$. In this study, Moran's map was used. Critical areas were those formed by municipalities included in Q1 as epidemiological indicators and in Q2 as operational indicators.

The TerraView software, version 4.2 (INPE, Sao Paulo, Brazil) was used for the processing, analysis and calculation of spatial autocorrelation indicators, and the QGIS software, version 2.14 (Open Source Geospatial Foundation, Chicago, USA) was used to present cartographic data and create thematic maps.

\section{RESULTS}

In the study, a total of 185 cases were excluded due to diagnostic errors, duplicate entries, missing data and inconsistencies. In addition to the completeness of data from the cases, after the overall analysis of database, 587 cases $(1.99 \%)$ were excluded. Thus, the study included 28,895 new leprosy cases.

Among the paucibacillary patients (according to the operational classification), there was a predominance of the female sex $(\mathrm{n}=9,286 ; 63.00 \%)$, those aged $\geq 15$ years old $(\mathrm{n}=12,556 ; 85.18 \%)$, grade zero physical disability $(\mathrm{n}=12,065 ; 81.85 \%)$, and cure as the treatment outcome $(\mathrm{n}=13,285 ; 90.13 \%)$. However, the percentage of individuals aged $<15$ years old was $14.82 \%(n=2.184)$, which is noteworthy. Among the multibacillary patients, a predominance of the male sex $(n=8,564 ; 60.70 \%)$, those aged $\geq 15$ years old $(n=13,226 ; 93.74 \%)$, grade zero physical disability $(\mathrm{n}=7,843 ; 55.59 \%)$ and cure as the treatment outcome ( $\mathrm{n}=11,535 ; 81.76 \%$ ) was observed (Table 2$)$. The percentages of paucibacillary and multibacillary patients with some degree of physical disability at diagnosis were $11.40 \%$ and $33.45 \%$, respectively (Table 2). All the evaluated variables were correlated with the operational classification $(\mathrm{p}<0.001)$ (Table 2). 
Table 2 - Demographic and clinical variables of new leprosy cases, according to the operational classification, in Pernambuco State, from 2005 to 2014.

\begin{tabular}{|c|c|c|c|c|c|}
\hline \multirow{3}{*}{ Variables } & \multicolumn{4}{|c|}{ Operational classification } & \multirow[t]{3}{*}{$P$-value } \\
\hline & \multicolumn{2}{|c|}{ Paucibacillary } & \multicolumn{2}{|c|}{ Multibacillary } & \\
\hline & $\mathrm{N}(14,740)$ & $\%$ & $\mathrm{~N}(14,109)$ & $\%$ & \\
\hline Sex & & & & & $<0.001$ \\
\hline Female & 9,286 & 63.00 & 5,545 & 39.30 & \\
\hline Male & 5,454 & 37.00 & 8,564 & 60.70 & \\
\hline Age group & & & & & $<0.001$ \\
\hline $0-14$ years & 2,184 & 14.82 & 883 & 6.26 & \\
\hline$\geq 15$ years & 12,556 & 85.18 & 13,226 & 93.74 & \\
\hline Degree of physical disability at diagnosis & & & & & $<0.001$ \\
\hline Grade 0 & 12,065 & 81.85 & 7,843 & 55.59 & \\
\hline Grade 1 & 1,501 & 10.18 & 3,430 & 24.31 & \\
\hline Grade 2 & 180 & 1.22 & 1,290 & 9.14 & \\
\hline Not assessed & 654 & 4.44 & 1,006 & 7.13 & \\
\hline Not known & 340 & 2.31 & 540 & 3.83 & \\
\hline Treatment outcome & & & & & $<0.001$ \\
\hline Cure & 13,285 & 90.13 & 11,535 & 81.76 & \\
\hline Transfers & 498 & 3.38 & 905 & 6.41 & \\
\hline Death & 55 & 0.37 & 293 & 2.08 & \\
\hline Abandonment & 732 & 4.97 & 940 & 6.66 & \\
\hline Not known & 170 & 1.15 & 436 & 3.09 & \\
\hline
\end{tabular}

The number of new cases, proportion of multibacillary patients, individuals aged $<15$ years old, as well as epidemiological and operational indicators of leprosy were analyzed according to the year of diagnosis, showing the following: the highest number of new cases was reported in $2006(3,297)$ and the lowest in $2014(2,546)$; the proportion of multibacillary patients was $44.19 \%$ in 2006 and reached $55.54 \%$ in 2014 ; the lowest number of patients aged $<15$ years old was reported in 2009 (9.95\%) and the highest in $2007(11.31 \%)$.

Regarding epidemiological indicators, the following was observed: annual detection rates were very high over the entire period, with 39.12 per 100,000 inhabitants in 2005 and 27.44 per 100,000 inhabitants in 2014. In the ten years of the study, for the indicative proportion of new cases with grade 2 physical disability the year 2007 stood out (6.38\%) among the six years presenting with this intermediate parameter of disability and the remaining four years had lower frequencies $(<5 \%)$; with regard to this operational indicator; the proportion of new cases with some degree of physical disability assessed at diagnosis was $>90 \%$ during the entire period, which indicated a good quality of health services; the proportion of examined household contacts was good ( $\geq 75 \%$ ), with the exception of the year 2005 , with an average of $69.30 \%$.

The Bayesian local empirical analysis showed that 7 (3.80\%) municipalities in health regions I, VIII, IX and XI were hyperendemic based on the overall detection rate (Figure 1A). Moran's global (I) index was 0.55 ( $\mathrm{p}<0.01$ ), thereby indicating the existence of spatial dependence. The Moran map yielded 22 (11.96\%) municipalities concentrated in three high-priority areas, distributed across health regions I, II, VIII, IX, and XII (Figure 1B).

The indicator rate of leprosy cases with grade 2 physical disability at the time of diagnosis with the Bayesian local empirical analysis showed a number of municipalities in which this parameter was high $(61 ; 33.15 \%)$ (Figure 2A), and the cluster with the highest number of municipalities was found in health regions II, III, IV, V and VI. The Global Moran's I index expressed positive spatial autocorrelation $(0.45 ; \mathrm{p}<0.01)$. The Moran map yielded $22(11.96 \%)$ municipalities of the high-high type in health regions IV, $\mathrm{V}$, and VI (Figure 2B).

The indicator rate of new leprosy cases with physical disability assessed at the time of diagnosis with the Bayesian local empirical method showed the formation of four 
A) Local Empiric Bayesian
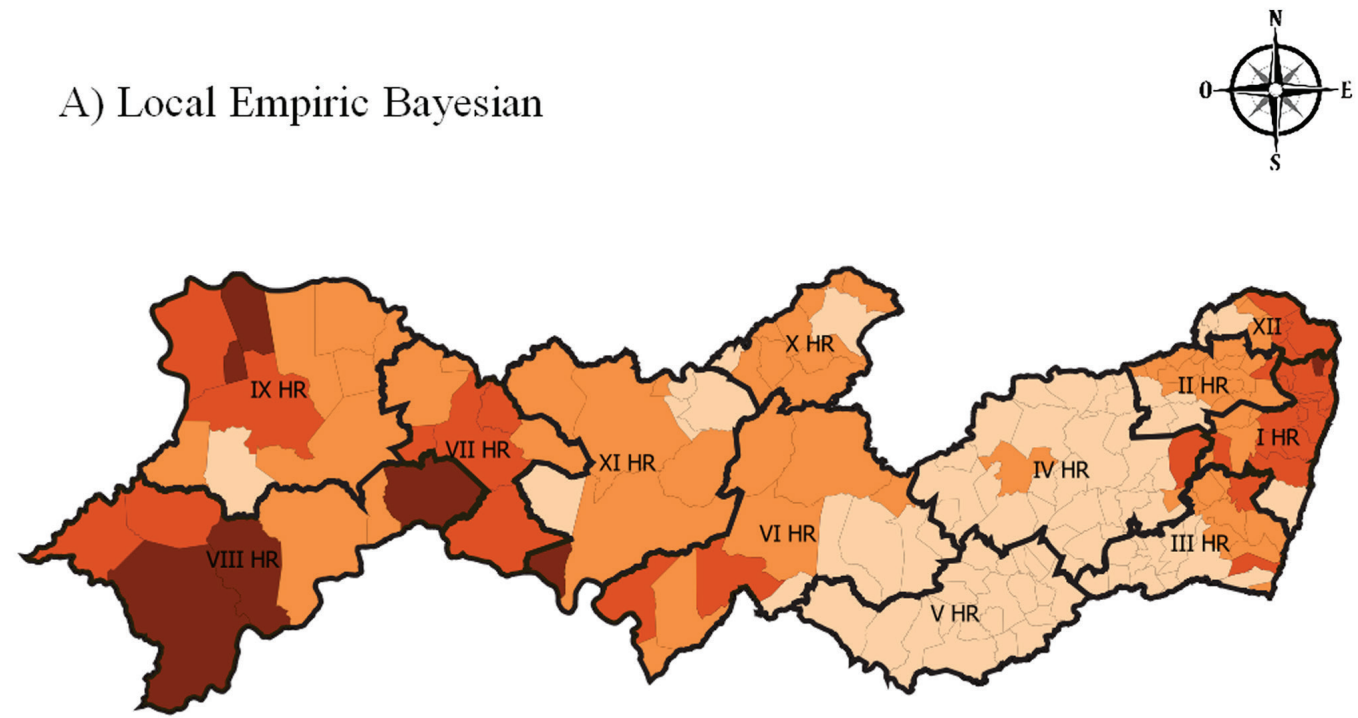

$\begin{array}{lllll}0 & 70 & 140 & 210 & 280 \mathrm{~km}\end{array}$

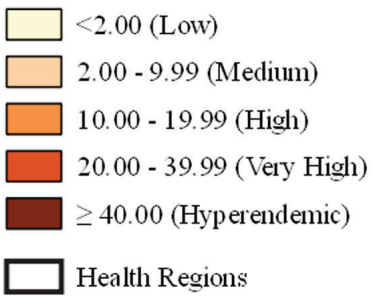

B) Moran Map
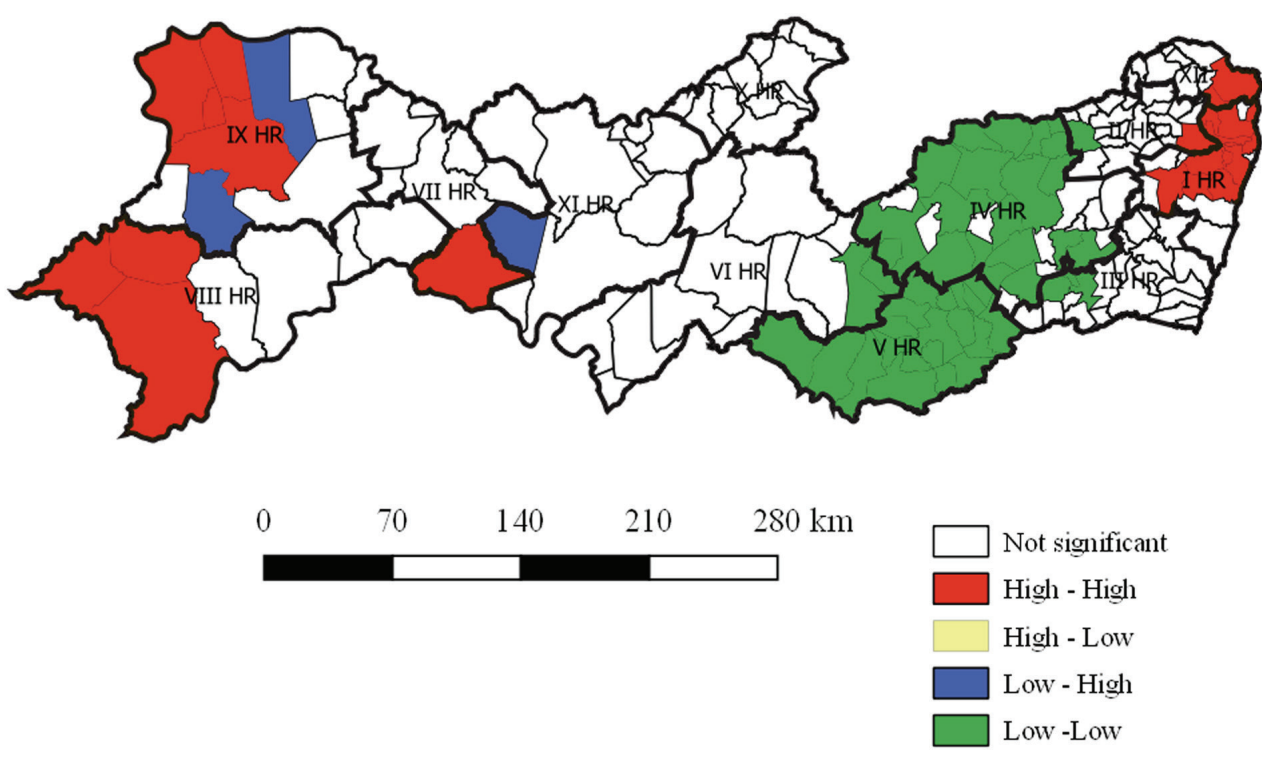

Health Regions

Figure 1 - Spatial analysis of the mean detection rate of new leprosy cases: rate smoothed by the Bayesian local empiric method (A) and Moran map (B), per 100,000 inhabitants and per municipality. Pernambuco State, Brazil, 2005-2014. 
A) Local Empiric Bayesian
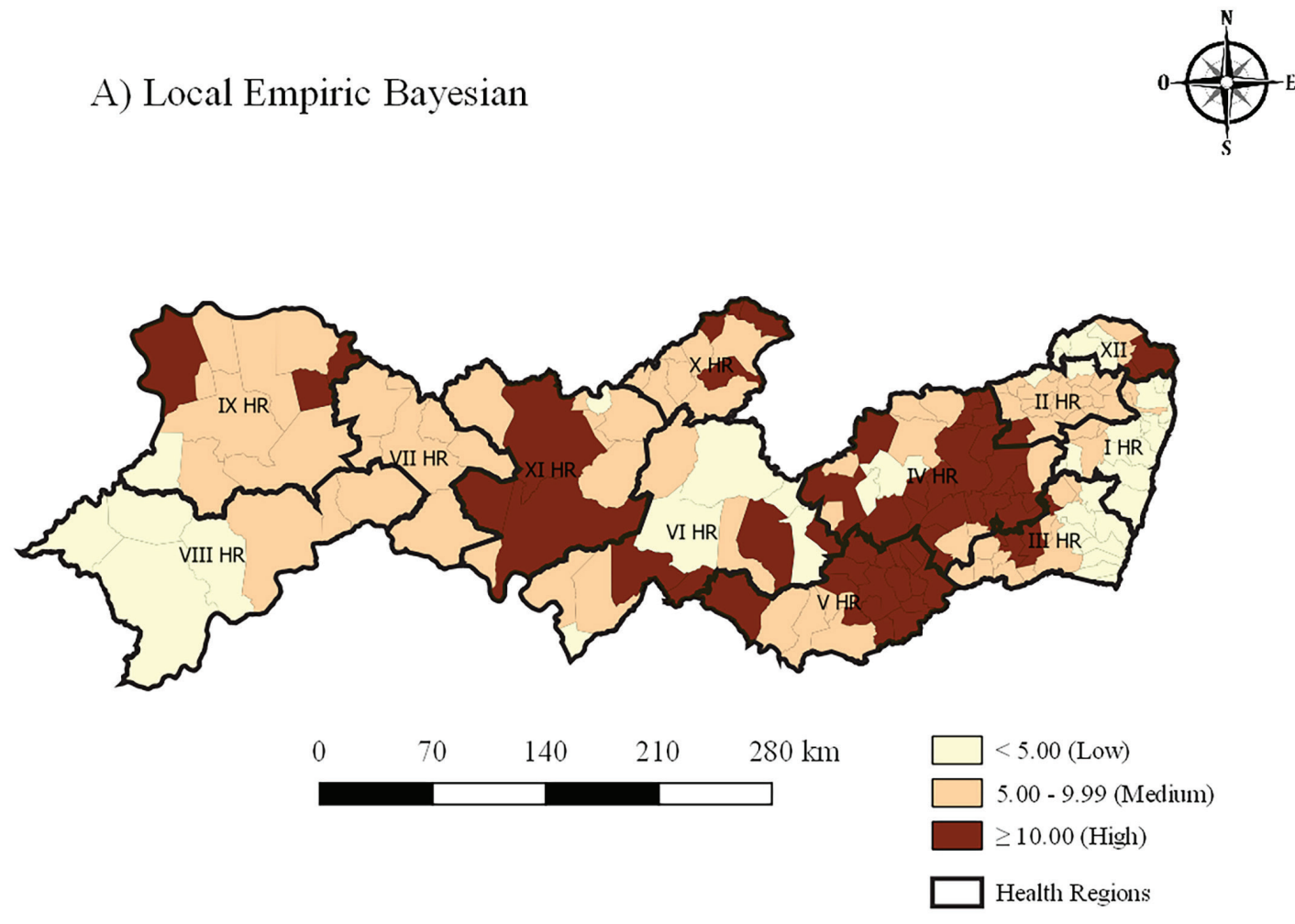

B) Moran Map
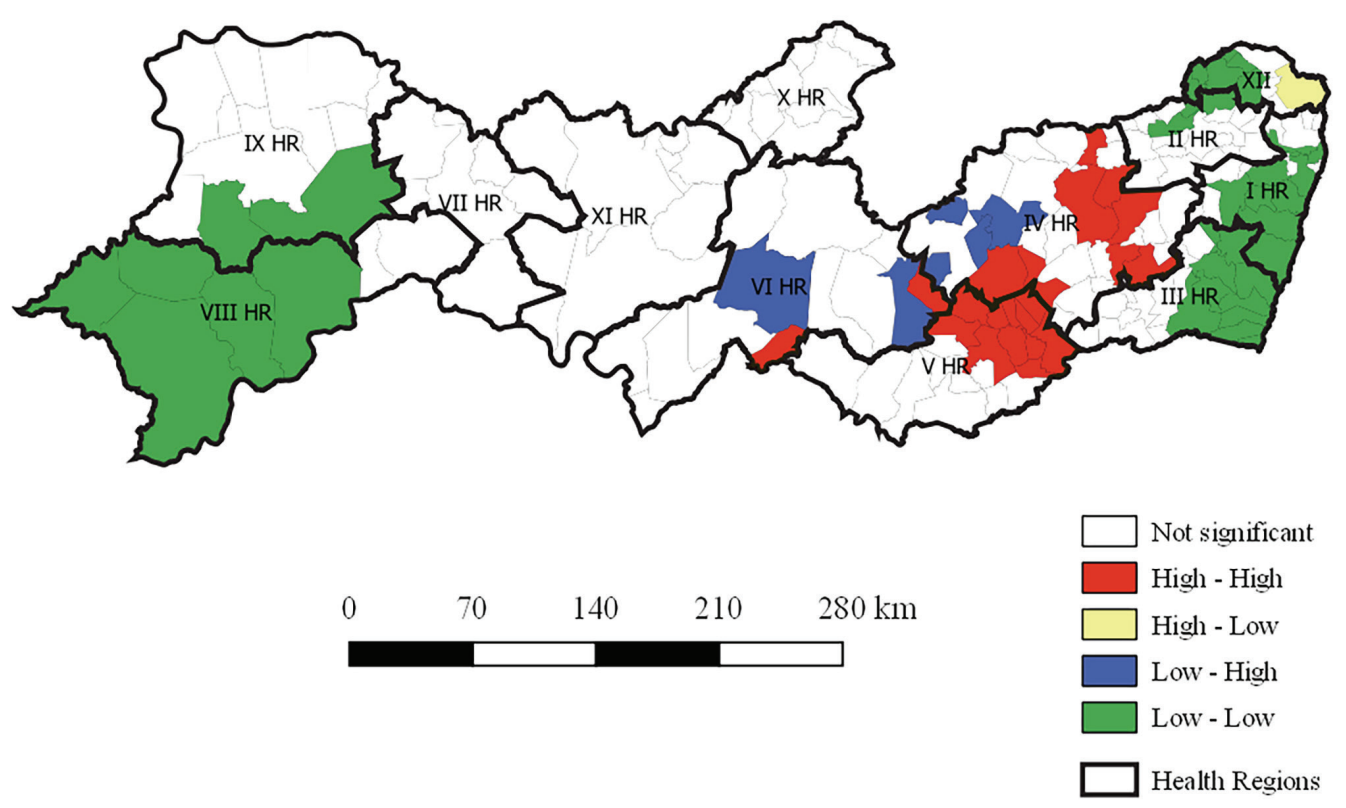

Figure 2 - Spatial analysis on the mean rate of leprosy cases with grade 2 physical disability at the time of diagnosis among new cases detected and evaluated:-rate smoothed by the Bayesian local empiric method (A) and Moran map (B). Pernambuco State, Brazil, 2005-2014. 
clusters in which the level of disability was intermediate, the greatest including $40(21.74 \%)$ municipalities distributed across health regions I, II, IV, and XII (Figure 3A). The global Moran's I index expressed a positive spatial autocorrelation $(0.74 ; \mathrm{p}<0.01)$. On the Moran's map, a high-priority area for intervention, with 37 (20.11\%) of municipalities distributed across health regions I, II, IV and XII, persisted (Figure 3B).

\section{DISCUSSION}

The present study revealed the profile of paucibacillary and multibacillary patients with predominance of the age group older than 15 years, with a zero degree of disability at the time of diagnosis and cured. There was a distinction in relation to sex, with females predominating in the paucibacillary group and males in the multibacillary one. Regarding the epidemiological and operational indicators, 2006 stood out with the highest number of new cases, 2014 with the highest proportion of multibacillary infections and 2017 with the hihest proportion of patients $>15$ years old. Although the detection rate decreased along the years, it remained high, and the indicator of the degree 2 of disability in six years continued as an intermediate parameter, the proportion of those with degree 2 of physical disability decreased and the proportion of those examined among household contacts increased over the years, translating a good quality of health services. The areas with high priority of intervention persisted in the municipalities in the I, III, VII and IX Health Regions.

A predominance of cases with more than five skin lesions (multibacillary) was observed among men, a result in line with those obtained in Cebu, Lapu-Lapu, Talisay and Mandaue cities (Philippines) ${ }^{1}$, Chengalpattu district

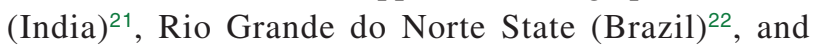
Buriticupu city (Brazil) ${ }^{23}$. In the latter report, the probability of multibacillary leprosy was almost twice as high among men as among women. A possible explanation is that men are more exposed to Mycobacterium leprae. In addition, some sociocultural factors (traditional beliefs, low status, limited mobility, illiteracy and insufficient knowledge on the disease) may account for the underreporting of multibacillary cases among women ${ }^{8,24}$.

The group aged $>15$ years old was shown as the most affected age group. This group includes older people who, in studies conducted in Brazil ${ }^{8}$, Mexico $^{25}$ and $\mathrm{Korea}^{26}$, were the most affected by the disease. In a study conducted in Maranhao (Brazil), the number of paucibacillary cases was 2.43 times higher among individuals aged $<15$ years than among those aged $\geq 60$ years $^{23}$. Similar to the findings of this study, $>10 \%$ of new leprosy cases among patients aged $<15$ years old are paucibacillary. This percentage is due to the fact that a lower number of lesions is expected at the initial presentation of the disease, because of the long incubation period of the etiological agent ${ }^{3}$.

The predominance of multibacillary patients is associated with late diagnosis and higher risk of physical disability, which contribute to maintain the chain of disease transmission ${ }^{27}$. Among the new leprosy cases, $11.40 \%$ and $33.45 \%$ were of paucibacillary and multibacillary patients, respectively, with some degree of physical disability at the time of diagnosis. In Sao Paulo (Brazil) ${ }^{28}, 60 \%$ of patients had physical disability at the time of diagnosis between 2001 and 2006, as was also observed in studies conducted in India ${ }^{29}$ and Colombia ${ }^{30}$. The high rate of physical disability may lead to complications of leprosy, including neuropathic pain $^{31}$.

Cured patients have been reported to present with some types of sequelae ${ }^{12}$. In this study, cure was the most frequent treatment outcome. In 2019, Assis et al. ${ }^{32}$ reported nervous and sensory system impairment upon diagnosis as risk factors for disability at the end of the polychemotherapy. Authors of another study reported deficiencies during treatment ${ }^{33}$. Treatment regimens based solely on the number of lesions (operational classification) may lead to errors and disease relapse, bacillary persistence, treatment failure and/or insufficiency ${ }^{34}$.

The proportion of multibacillary patients increased over the study period. Results are in line with national data from 2003 to 2013, a period during which a gradual reduction in the annual detection rate was observed with an increase in the percentage of new multibacillary cases $^{8}$, which may have an impact on the chain of disease transmission.

The proportion of children aged $<15$ years old varied over the study period. Children are considered the most vulnerable group for $M$. leprae infection ${ }^{35}$. Therefore, it is essential to assess the occurrence of leprosy in this age group, as it reflects the intensity of the infectious agent propagation $^{36}$.

The annual detection rate of new cases remained very high over the entire study period, which indicates a high disease endemicity in Pernambuco State. The spatial distribution showed three clusters in five health regions (I, II, VIII, IX and XII). The value of the indicator rate with grade 2 physical disability, which indicates the opportunity for the diagnosis of leprosy was intermediate over the years, and low values were only detected in 4 years of the period. The spatial analysis allowed the identification of clusters of municipalities in which this parameter was high, especially in areas that had not yet been identified, such as in health regions IV, $\mathrm{V}$, and $\mathrm{X}$. This demonstrates the hidden 

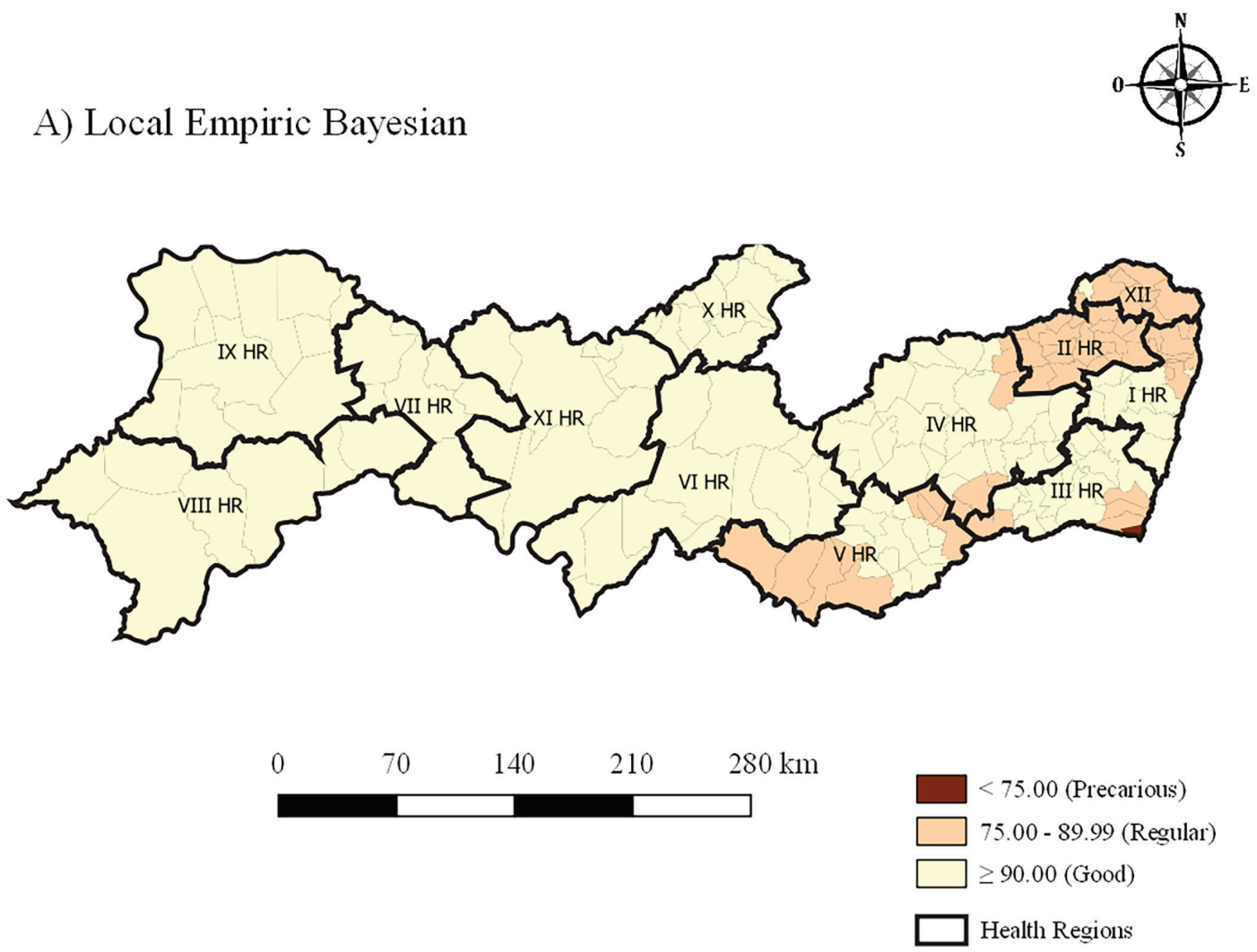

B) Moran Map
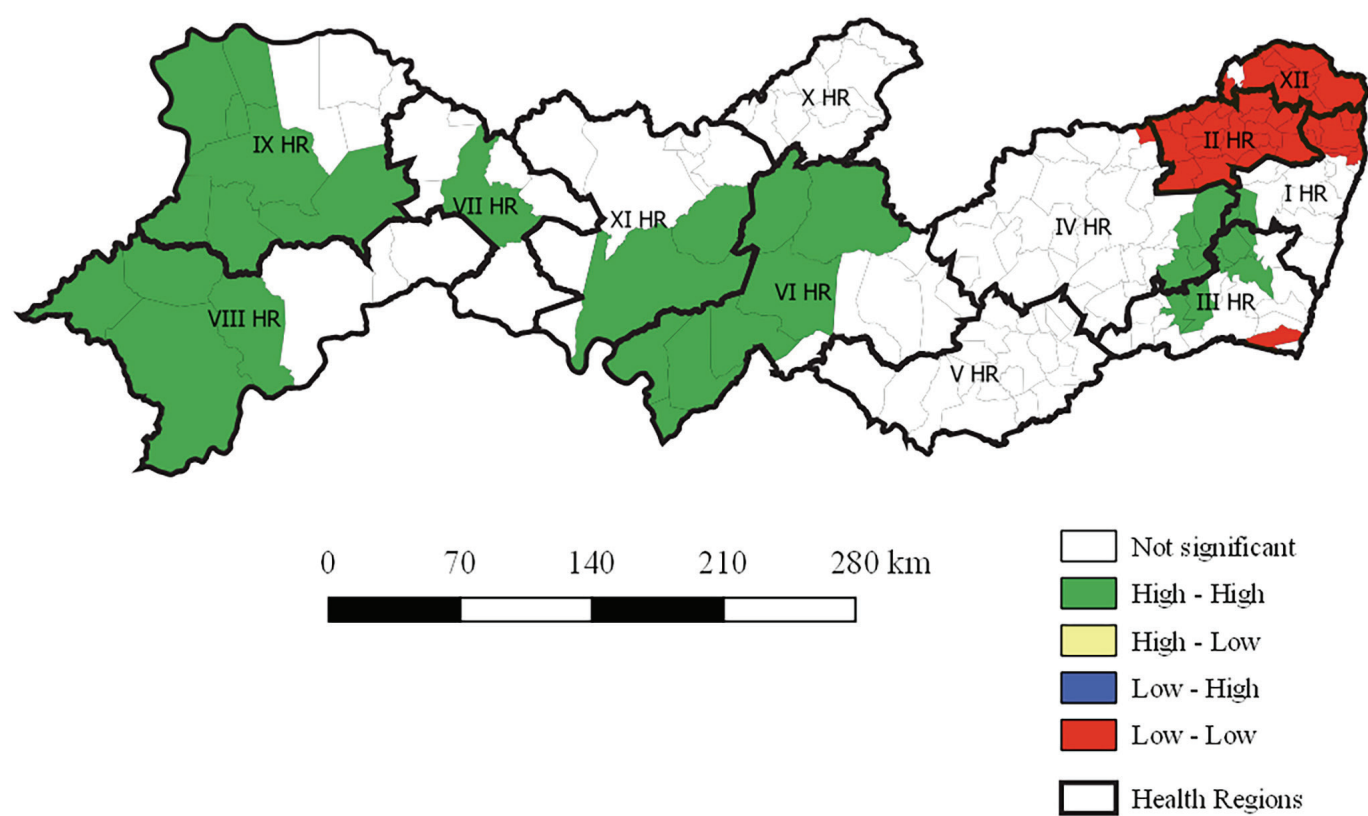

Figure 3 - Spatial analysis on the mean rate of new leprosy cases with some degree of physical disability assessed at the time of diagnosis: rate smoothed by the Bayesian local empiric method (A) and Moran map (B), per municipality. Pernambuco State, Brazil, 2005-2014. 
prevalence and late diagnosis that interfere with the early detection of leprosy ${ }^{19}$.

The values of the operational indicators that assess the quality of the State's health services over the years were good. It is worth noting that health services are decentralized by means the Family Health Program (Estrategia Saude da Familia) teams, which contribute to the reorganization of the care provided to patients with leprosy ${ }^{37}$. This decentralization aims at improving the organization of demand, as well as the population's understanding of the disease and how to access a health center to be diagnosed, treated and eventually cured ${ }^{38}$. Activities of the Family Health Program contribute to increasing the populations' access to healthcare services in Brazil ${ }^{37,38}$.

The spatial distribution analysis on the rate of physical disability detected at the time of diagnosis showed 40 $(21.74 \%)$ municipalities in which this parameter was intermediate, in eight health regions. After using the Moran map, the priority areas of intervention were apparent, with an area composed of 37 municipalities in health regions I, II, IV and XII. This suggests a deficient quality of care in the health services of these localities.

It is worth noting that Regions I, IV and IX had the worst percentages of population coverage estimated by the Family Health teams ${ }^{13}$, and this may have jeopardized the timely diagnosis in these locations. In addition, the lowest mean values of Life Expectancy at Birth, the Human Development Index (HDI), the percentage of literacy in the $\mathrm{V}$ region and the low water supply, sanitation and GDP in the IX region ${ }^{13}$, are characteristics of underdeveloped areas susceptible to neglected diseases such as leprosy.

In this study, indicator rates of examined household contacts were good in most years. This indicator assesses the capacity of health services to perform contact surveillance for the detection of new cases ${ }^{39}$. Household contacts are at a higher risk of contracting leprosy due to the prolonged time spent with undiagnosed multibacillary patients ${ }^{18}$. The focus should be placed not only on household contacts, but also on a wider spectrum of social contact networks ${ }^{39}$. However, the good result obtained for this parameter is in contrast with that of the spatial analyses that showed most vulnerable areas to the disease and allowed the assessment on the quality of assistance to patients with leprosy.

The interpretation of results should be carefully considered as this study had limitations regarding the use of secondary data, which may lead to inconsistency regarding data quantity, quality and processing. However, to minimize these limitations, duplicate and missing data were detected, as well as inconsistencies in notification forms, and these cases were excluded from the database. Information obtained from the SINAN contributed to the characterization of the epidemiological situation of a given area. This is the only available system that integrates epidemiological data on diseases.

The results point to an expected characterization as the largest portion of affected people were the oldest, at the time of assessing the degree of disability it was grade zero and the majority were cured. However, when the epidemiological and operational indicators were analyzed in addition to spatial standards, it was observed that the Pernambuco State continues to have high parameters, possible failures in health services, as well as the transmissibility of the active disease, especially in the municipalities flagged as priority.

Thus, this study indicate that the chain of leprosy transmission remains active, and endemicity is ongoing in Pernambuco State. Therefore, further investments are required to improve the efficacy of health services regarding the early diagnosis of leprosy, timely initiation of treatment and systematic and qualified assessment of household contacts. The aim is to prevent physical deformities caused by this disease and avoid new cases, ultimately reaching the elimination targets in Brazil.

\section{ACKNOWLEDGMENTS}

This study was financed in part by the Coordenação de Aperfeiçoamento de Pessoal de Nivel Superior - Brasil (CAPES) - Finance Code 001.

\section{CONFLICT OF INTERESTS}

The authors report no conflict of interests. They alone are responsible for the content and writing of this article.

\section{FINANCIAL SUPPORT}

This study was financed in part by the Coordination for the Improvement of Higher Education Personnel - Brazil (CAPES) - Finance Code 001.

\section{REFERENCES}

1. Scheelbeek PF, Balagon MV, Orcullo FM, Maghanoy AA, Abellana J, Saunderson PR. A retrospective study of the epidemiology of leprosy in Cebu: an eleven-year profile. PLoS Negl Trop Dis. 2013;7:e2444.

2. Alemu Belachew W, Naafs B. Position statement: leprosy: diagnosis, treatment and follow-up. J Eur Acad Dermatol Venereol. 2019;33:1205-13

3. Moreira SC, Batos CJ, Tawil L. Epidemiological situation of leprosy in Salvador from 2001 to 2009. An Bras Dermatol. 2014;89:107-17. 
4. Brasil. Ministério da Saúde. Secretaria de Vigilância em Saúde. Departamento de Vigilância das Doenças Transmissíveis. Diretrizes para vigilância, atenção e eliminação da hanseníase como problema de saúde pública. Brasília: Ministério da Saúde; 2016. [cited 2020 Oct 7]. Available from: http:// portalarquivos2.saude.gov.br/images/pdf/2016/fevereiro/04/ diretrizes-eliminacao-hanseniase-4fev16-web.pdf

5. World Health Organization. Global leprosy strategy 2016-2020: accelerating towards a leprosy-free world. Geneva: WHO; 2016. [cited 2020 Oct 7]. Available from: https://www.who. int/lep/resources/9789290225096/en/

6. Bharucha T, Lockwood D. Leprosy in the UK. Br J Hosp Med (Lond). 2016;77:C154-6.

7. Blok DJ, Crump RE, Sundaresh R, Ndeffo-Mbah M, Galvani AP, Porco TC, et al. Forecasting the new case detection rate of leprosy in four states of Brazil: a comparison of modelling approaches. Epidemics. 2017;18:92-100.

8. Nobre ML, Illarramendi X, Dupnik KM, Hacker MA, Nery JA, Jerônimo SM, et al. Multibacillary leprosy by population groups in Brazil: lessons from an observational study. PLoS Neg1 Trop Dis. 2017;11:e0005364.

9. Brito KK, Andrade SS, Santana EM, Peixoto VB, Nogueira JA, Soares MJ. Epidemiological analysis of leprosy in an endemic state of northeastern Brazil. Rev Gaucha Enferm. 2015;36 N Esp:24-30.

10. Barbosa CC, Bonfim CV, Brito CM, Ferreira AT, Gregório VR, Oliveira AL, et al. Spatial analysis of reported new cases and local risk of leprosy in hyper-endemic situation in Northeastern Brazil. Trop Med Int Health. 2018;23:748-57.

11. Ramos AC, Yamamura M, Arroyo LH, Popolin MP, Chiaravalloti Neto F, Palha PF, et al. Spatial clustering and local risk of leprosy in São Paulo, Brazil. PLoS Negl Trop Dis. 2017;11:e0005381.

12. Barbosa DR, Almeida MG, Santos AG. Características epidemiológicas e espaciais da hanseníase no Estado do Maranhão, Brasil, 2001-2012. Medicina (Ribeirao Preto). 2014;47:347-56.

13. Pernambuco. Governo do Estado. Secretaria Estadual de Saúde. Cadernos de informação em saúde: caderno 2019. [cited 2020 Oct 7]. Available from: http://portal.saude.pe.gov.br/aplicativo/ secretaria/cadernos-de-informacoes-em-saude

14. Galvão PR, Ferreira AT, Maciel MG, Almeida RP, Hinders D, Schreuder PA, et al. An evaluation of the Sinan health information system as used by the Hansen's disease control programme, Pernambuco State, Brazil. Lepr Rev. 2008;79:17182.

15. Oliveira ME, Soares MR, Costa MC, Mota EL. Avaliação da completitude dos registros de febre tifóide notificados no Sinan pela Bahia. Epidemiol Serv Saude. 2009;18:219-26.

16. Brasil. Ministério da Saúde. Gabinete do Ministro. Portaria $\mathrm{n}^{\mathrm{o}} 3.125$ de 7 de outubro de 2010. Aprova as diretrizes para vigilância, atenção e controle da hanseníase. Diário Oficial da União, Brasília. 15 out. 2010.

17. Instituto Brasileiro de Geografia e Estatística. Estimativas de população: downloads. [cited 2020 Oct 7]. Available from: https://www.ibge.gov.br/estatisticas/sociais/populacao/9103estimativas-de-populacao.html?=\&t=downloads

18. Assunção RM, Barreto SM, Guerra HL, Sakurai E. Mapas de taxas epidemiológicas: uma abordagem Bayesiana. Cad Saude Publica 1998;14:713-23

19. Monteiro LD, Martins-Melo FR, Brito AL, Alencar CH, Heukelbach J. Spatial patterns of leprosy in a hyperendemic state in Northern Brazil, 2001-2012. Rev Saude Publica 2015;49:84.

20. Anselin L. Local indicators of spatial association - LISA. Geogr Anal. 1995;27:93-115.

21. Joshua V, Mehendale S, Gupte MD. Bayesian model, ecological factors \& transmission of leprosy in an endemic area of South India. Indian J Med Res. 2016;143:104-6.

22. Moreno CM, Azevedo IC, Luna FD, Silva RC, Lima JV, Aquino LA, et al. Temporal analysis of a case series of leprosy patients from a low endemic area in Brazil and the magnitude of disability. Int Arch Med. 2016;9:178.

23. Silva AR, Lima Neto PM, Santos LH, Lima RJ, Tauil PL, Gonçalves EG. Factors associated with leprosy in a municipality of the Pre-Amazon region, state of Maranhão, Brazil. Rev Soc Bras Med Trop. 2018;51:789-94.

24. Sarkar R, Pradhan S. Leprosy and women. Int J Womens Dermatol. 2016;2:117-21.

25. Larrea MR, Carreño MC, Fine PE. Patterns and trends of leprosy in Mexico: 1989-2009. Lepr Rev. 2012;83:184-94.

26. Lee J, Kim JP, Nishikiori N, Fine PE. The decline of leprosy in the Republic of Korea; patterns and trends 1977-2013. Lepr Rev. 2015;86:316-27.

27. Lima LN, Frota CC, Mota RM, Almeida LF, Pontes AA, Sá G, et al. Widespread nasal carriage of Mycobacterium leprae among a healthy population in a hyperendemic region of northeastern Brazil. Mem Inst Oswaldo Cruz. 2015;110:898-905.

28. Alves CJ, Barreto JA, Fogagnolo L, Contin LA, Nassif PW. Avaliação do grau de incapacidade dos pacientes com diagnóstico de hanseníase em serviço de dermatologia do estado de São Paulo. Rev Soc Bras Med Trop. 2010;43:460-1.

29. Sarkar J, Dasgupta A, Dutt D. Disability among new leprosy patients, an issue of concern: an institution based study in an endemic district for leprosy in the state of West Bengal, India. Indian J Dermatol Venereol Leprol. 2012;78:328-34.

30. Guerrero MI, Muvdi S, León CI. Retraso en el diagnóstico de lepra como factor pronóstico de discapacidad en una cohorte de pacientes en Colombia, 2000 - 2010. Rev Panam Salud Publica. 2013;33:137-43.

31. Ramos JM, Alonso-Castañeda B, Eshetu D, Lemma D, Reyes F, Belinchón I, et al. Prevalence and characteristics of neuropathic 
pain in leprosy patients treated years ago. Pathog Glob Health 2014;108:186-90.

32. Assis BP, Lyon S, Grossi MA, Rocha MC. Risk factors for physical disability upon release from multidrug therapy in new cases of leprosy at a referral center in Brazil. Rev Inst Med Trop Sao Paulo. 2019;61:e13.

33. Moschioni C, Antunes CM, Grossi MA, Lambertucci JR. Risk factors for physical disability at diagnosis of 19,283 new cases of leprosy. Rev Soc Bras Med Trop. 2010;43:19-22.

34. Porto AC, Figueira RB, Barreto JA, Lauris JR. Evaluation of the social, clinical and laboratorial profile of patients diagnosed with leprosy in a reference center in São Paulo. An Bras Dermatol. 2015;90:169-77.

35. Souza CD, Rodrigues M. Magnitude, tendência e espacialização da hanseníase em menores de 15 anos no estado da Bahia, com enfoque em areas de risco: um estudo ecológico. Hygeia. 2015;11:201-12
36. Queirós MI, Ramos Júnior AN, Alencar CH, Monteiro LD, Sena AL, Barbosa JC. Clinical and epidemiological profile of leprosy patients attended at Ceará, 2007-2011. An Bras Dermatol. 2016;91:311-17.

37. Barbieri RR, Sales AM, Hacker MA, Nery JA, Duppre NC, Machado AM, et al. Impact of a Reference Center on Leprosy Control under a Decentralized Public Health Care Policy in Brazil. PLoS Negl Trop Dis. 2016;10:e0005059.

38. Lapa TM, Albuquerque MF, Carvalho MS, Silveira Júnior JC. Análise da demanda de casos de hanseníase aos serviços de saúde através do uso de técnicas de análise espacial. Cad Saude Publica. 2006;22:2575-83.

39. Romero-Montoya M, Beltran-Alzate JC, Cardona-Castro N. Evaluation and monitoring of Mycobacterium leprae transmission in household contacts of patients with Hansen's disease in Colombia. PLoS Negl Trop Dis. 2017;11:e005325. 